\title{
MicroRNA-195 suppresses cell proliferation, migration and invasion in epithelial ovarian carcinoma via inhibition of the CDC42/CCND1 pathway
}

\author{
XIAOYING HAO, QINGQING JIA, JIELING YUAN, XIANGRONG SHI, HUIHUI GUO, \\ JIEFANG GAO and YE GUO \\ Department of Obstetrics and Gynecology, The Second Hospital of Shanxi Medical University, \\ Taiyuan, Shanxi 030001, P.R. China
}

Received December 17, 2019; Accepted July 29, 2020

DOI: $10.3892 /$ ijmm.2020.4716

\begin{abstract}
Epithelial ovarian carcinoma (EOC) is the most common cause of gynecological cancer mortality, and poses a threat to women. MicroRNA-195 (miR-195) has been reported to induce apoptosis of human OVCAR-3 cells by inhibiting the VEGFR2/AKT pathway. However, the role of miR-195 in EOC remains unknown. A previous study reported that cell division cycle 42 (CDC42) can serve as a target gene of miR-195 and mediate malignant progression of esophageal squamous cell carcinoma (ESCC). The aim of the present study was to investigate the role of miR-195 in EOC and the regulation in CDC42/CCND1 pathway. Tissues samples and clinical materials were collected from 78 enrolled patients with EOC to analyze the expression and clinical significance of miR-195, CDC42 and cyclin D1 (CCND1). Human EOC cell lines OVCA420, OVCAR-3, A2780 and SKOV3 cell lines were used to assess the expression and function of miR-195, CDC42 and CCND1 in vitro. Cell proliferation, the cell cycle and apoptosis, as well as the cell migratory and invasive abilities were detected in vitro using BrdU incorporation, colony formation, wound healing and Transwell invasion assays, along with flow cytometry. miR-195 was downregulated, while CDC42 and CCND1 were upregulated in human EOC tissues and cells, and the aberrant expression of both was associated with increased EOC malignancy. Moreover, miR-195 expression was negatively correlated with CDC42 and CCND1 expression levels, and negatively regulated these expression levels. Thus, it was suggested that miR-195 functions as a tumor suppressor, but CDC42 and CCND1 act as tumor promoters based their abilities to enhance cell proliferation, cell cycle
\end{abstract}

Correspondence to: Mrs Xiaoying Hao, Department of Obstetrics and Gynecology, The Second Hospital of Shanxi Medical University, 382 Wuyi Road, Taiyuan, Shanxi 030001, P.R. China

E-mail: haoxiaoyingms@163.com

Key words: epithelial ovarian carcinoma, microRNA-195/cell division cycle 42/cyclin D1, proliferation, migration, invasion entry, migration and invasion, as well as decrease apoptosis in OVCAR-3 cells. the present results demonstrated that miR-195 inhibited human EOC progression by downregulating CDC42 and CCND1 expression. Furthermore, it was identified that miR-195, CDC42 and CCND1 may be effective biomarkers for EOC diagnosis and treatment.

\section{Introduction}

Ovarian cancer (OC) is one of the most common malignancies of the female reproductive organs. For instance, its morbidity is second only to cervical cancer and corpus carcinoma; however, the mortality of OC ranks first (1). The 5-year survival rates of OC are $\sim 90$ and $\sim 15 \%$ in the early and advanced phases, respectively (2). OC can be divided into epithelial, germ and stromal cell neoplasms (3). Epithelial ovarian carcinoma (EOC), which accounts for $>70 \%$ of the cases of $\mathrm{OC}$, has a $30 \%$ 5-year survival rate and the highest mortality rate among all gynecological tumors worldwide, and therefore, poses a serious threat to women $(4,5)$. As ovary tumor tissues are small and reside deeply in the pelvic cavity, and patients lack typical symptoms, the diagnosis of EOC during the early stage is very difficult. Moreover, $<30 \%$ of patients with EOC are reported to have tumors confined to the ovary during surgery; the majority of tumors spread to the pelvic and abdominal organs, and thus, early diagnosis is important (6). However, EOC typically presents at an advanced stage, leading to an elevated mortality rate (7). Considering the difficulty in early diagnosis and the distinctive metastasis of EOC, investigating the biological and molecular mechanisms of advance metastasis is crucial for the development of effective therapeutic approaches against EOC (8).

MicroRNAs (miRNAs/miRs) are short, single-stranded, non-coding RNAs present in different tissues and bodily fluids that can regulate target gene expression post-transcriptionally. Previous studies have reported that miRNAs are abnormally expressed in various tumors and can act as tumor suppressors or oncogenes, with roles in tumor development via negative regulation of specific genes (9-11). For example, miR-195 has been observed to be downregulated in EOC, and was revealed to decrease cell proliferation and induce apoptosis 
of human OVCAR-3 cells by inhibiting VEGFR2 and AKT signaling (12). In addition, miR-195 is downregulated in human laryngeal squamous cell carcinoma, while the overexpression of miR-195 inhibits cell viability, migration and invasion, as well as promotes apoptosis of AMC-HN-8 cells (13). However, the roles of miR-195 in the cell cycle, migration and invasion of EOC cells are yet to be fully elucidated.

Cell division cycle 42 (CDC42) has been identified as a target gene of miR-195 (14). miR-195 expression is downregulated after overexpression of CDC42 in esophageal squamous cell carcinoma (ESCC), and the combined aberrant expression of miR-195 and CDC42 could predict malignant progression and unfavorable prognosis of ESCC (15). Furthermore, downregulated expression of miR-195, but upregulated cyclin D1 (CCND1) expression has been observed in papillary thyroid carcinoma (PTC) cells, and miR-195 inhibits tumor growth and metastasis in PTC by targeting CCND1 and fibroblast growth factor 2 (16). CDC42/CCND1 signaling pathways are also involved in endothelial cell migration and proliferation (17). However, it remains to be determined whether the CDC42/CCND1 pathway serves a role in EOC, and whether miR-195 acts as a tumor inhibitor in EOC by targeting the CDC42/CCND1 signaling pathway.

The present study hypothesized that miR-195 may suppress cell proliferation, migration and invasion in EOC via inhibition of the CDC42/CCND1 pathway.

\section{Materials and methods}

Patients and tumor tissues. Human EOC tumor tissues and adjacent non-tumor tissues were obtained from 78 patients (mean age, 52.33 \pm 9.87 years; age range, $42-60$ years) diagnosed with EOC via pathology, and who had undergone surgical excision with no prior anticancer treatments at The Second Hospital of Shanxi Medical University between January 2018 and December 2018. After resection, tissues were immediately snap-frozen in liquid nitrogen and stored at $-80^{\circ} \mathrm{C}$ for the following experiments. The clinical cases of the patients were acquired to analyze the association between miR-195, CDC42 and CCND1 expression levels and age, differentiation degree, TNM staging, serum CA12-5 content and International Federation of Gynecology and Obstetrics (FIGO) staging. The present work was approved by the Clinical Ethical Committee of The Second Hospital of Shanxi Medical University and written informed consent was obtained from all patients before the start of the study.

Cell culture. The wild-type human ovarian epithelial cell line HS832.Tc, and human EOC cell lines OVCA420, OVCAR-3, A2780 and SKOV3, were purchased from the Cell Bank of Chinese Academy of Sciences. All cells were cultured in DMEM (Sigma-Aldrich; Merck KGaA) or RPMI 1640 (Invitrogen; Thermo Fisher Scientific, Inc.) with 10\% FBS (Sigma-Aldrich; Merck KGaA) and $0.5 \%$ penicillin or streptomycin and maintained in a $5 \% \mathrm{CO}_{2}$ humidified chamber at $37^{\circ} \mathrm{C}$.

Reverse transcription-quantitative PCR (RT-qPCR). RT-qPCR was conducted to determine miR-195 expression in tissues and cells, as well as to determine CDC42 and CCND1
mRNA expression levels in OVCAR-3 cells, as previously described (12). Total RNA was isolated using TRIzol ${ }^{\circledR}$ reagent (Invitrogen; Thermo Fisher Scientific,Inc.) at room temperature, according to the manufacturer's instructions. Following cDNA synthesis using the TaqMan ${ }^{\mathrm{TM}}$ miRNA Reverse Transcription kit (Applied Biosystems; Thermo Fisher Scientific, Inc.) at $65^{\circ} \mathrm{C}$ for $1 \mathrm{~h}$. PCR was performed using TaqMan ${ }^{\mathrm{TM}}$ miRNA assay (Invitrogen; Thermo Fisher Scientific, Inc.) under the following thermocycling conditions for 42 cycles: Initial denaturation at $95^{\circ} \mathrm{C}$ for $5 \mathrm{~min}$, followed by 40 cycles of $94^{\circ} \mathrm{C}$ for $30 \mathrm{sec}, 65^{\circ} \mathrm{C}$ for $30 \mathrm{sec}, 72^{\circ} \mathrm{C}$ for $30 \mathrm{sec}$, and a final extension step at $72^{\circ} \mathrm{C}$ for $5 \mathrm{~min}$. Relevant primer sequences: hsa-miR-195 forward, 5'-ACACTCCAGCTGGGTAGCAGC ACAGAAAT-3' and reverse, 5'-TGGTGTCGTGGAGTCG-3'; human U6 (used as an internal control of miR-195) forward, 5'-CTCGCTTCGGCAGCACA-3' and reverse, 5'-AACGCT TCACGAATTTGCGT-3'; human CDC42 forward, 5'-GCC CGTGACCTGAAGGCTGTCA-3' and reverse, 5'-TGCTTT TAGTATGATGCCGACACCA-3'; human CCND1 forward, 5'-TCCTACTACCGCCTCACA-3' and reverse, 5'-ACC TCСТССТССТССТСТ-3'; and human GAPDH (used as an internal control of CDC42 and CCND1) forward, 5'-AAGGTG AAGGTCGGAGTCA-3' and reverse, 5'-GGAAGATGGTGA TGGGATTT-3'. Relative quantification was performed using the $2^{-\Delta \Delta \mathrm{Cq}}$ method (18).

Western blotting. Western blotting was performed to detect the protein expression levels of CDC42 and CCND1 from tissues and cells, as previously described (13). Total proteins were extracted with RIPA buffer (Beyotime Institute of Biotechnology). The BCA kit (Beyotime Institute of Biotechnology) was used to determine the concentration. In total, $80 \mu \mathrm{g}$ of each sample were resolved using $10 \%$ SDS-PAGE at $75 \mathrm{~V}$ for $2 \mathrm{~h}$. After transfer to PVDF membranes at $350 \mathrm{~mA}$ for $2 \mathrm{~h}$, membranes were blocked with $5 \%$ skim milk diluted in TBS for $1 \mathrm{~h}$ at room temperature. The membranes were probed overnight at $4^{\circ} \mathrm{C}$ with the following primary antibodies: Monoclonal anti-CDC42 (rabbit; 1:1,000; cat. no. 2466S; Cell Signaling Technology, Inc.), monoclonal anti-CCND1 (rabbit; 1:1,000; cat. no. 3300S; Cell Signaling Technology, Inc.) and monoclonal anti-GAPDH (rabbit; 1:1,000; cat. no. 5174S; Cell Signaling Technology, Inc.; used as an internal control). After probing with horseradish peroxidase (HRP)-conjugated secondary antibody (goat anti-rabbit IgG; 1:5,000; cat. no. TA130059; OriGene Technologies, Inc.) at room temperature for $1 \mathrm{~h}$, proteins were detected using an enhanced chemiluminescence reagent (Bio-Rad Laboratories, Inc.), and an Alpha Innotech instrument (Bio-Rad Laboratories, Inc.) was used to scan and quantify the images. GAPDH was used to normalize the signals.

Immunohistochemistry. The human EOC tumor tissues and adjacent non-tumor tissues were collected, fixed with $4 \%$ paraformaldehyde at $25^{\circ} \mathrm{C}$ for $24 \mathrm{~h}$ and dehydrated with a sucrose solution (gradient, 10, 20 and 30\%) at room temperature. After the tissues were harvested and dehydrated with $30 \%$ sucrose overnight, these were sectioned at $15-\mu \mathrm{m}$ thickness using a freezing microtome (Leica CM1900; Leica Microsystems $\mathrm{GmbH}$ ). The sections were washed three times for $5 \mathrm{~min}$ each time in $0.01 \mathrm{M}$ PBS. The endogenous oxidase 
activity was blocked with $3 \%$ hydrogen peroxide at $25^{\circ} \mathrm{C}$ in a closed environment for $15 \mathrm{~min}$. Then, sections were washed three times (5 min/time) with PBS and incubated with $2 \%$ goat serum (Sigma-Aldrich; Merck $\mathrm{KGaA}$ ) at $37^{\circ} \mathrm{C}$ in a wet box for $20 \mathrm{~min}$. The antigen retrieval protocol was performed at $95^{\circ} \mathrm{C}$ in a microwave for $15 \mathrm{~min}$ with $0.01 \mathrm{M}$ citrate buffer ( $\mathrm{pH} \mathrm{6.0).} \mathrm{The} \mathrm{tissue} \mathrm{sections} \mathrm{were} \mathrm{then} \mathrm{incubated} \mathrm{for} 30 \mathrm{~min}$ at $37^{\circ} \mathrm{C}$ in a water bath, followed by overnight incubation at $4^{\circ} \mathrm{C}$ with a polyclonal CDC42 antibody (rabbit; 1:300; cat. no. 2462S, Santa Cruz Biotechnology, Inc.) or a polyclonal CCND1 antibody (rabbit; 1:200; cat. no. 12531S, Santa Cruz Biotechnology, Inc.). After washing with $0.1 \mathrm{~mol} / 1 \mathrm{PBS}$ three times for $5 \mathrm{~min}$, the sections were incubated for $30 \mathrm{~min}$ at $37^{\circ} \mathrm{C}$ with HRP-conjugated goat anti-rabbit IgG secondary antibody (1:5,000; cat. no. W10814; Thermo Fisher Scientific, Inc.), followed by three washes for $5 \mathrm{~min}$ with $0.1 \mathrm{~mol} / 1$ PBS and added liquid detergent. The 3,3'-diaminobenzidine staining reaction was performed at room temperature for $30 \mathrm{sec}$, followed by the addition of hematoxylin at room temperature for $15 \mathrm{~min}$ for counterstaining and differentiation for $1 \mathrm{sec}$. The negative control was PBS. After the slides were naturally dried, sealed the slides with neutral resin (Beyotime Institute of Biotechnology). Observation was performed under light microscope at $\mathrm{x} 40$ magnification and analysis was performed using ImageJ software (v1.8.0, National Institutes of Health).

RNA interference and transfection assays. For overexpression or knockdown of miR-195, miR-195 mimic (5'-UAGCAG CACAGAAAUAUUGGC-3'), miR-195 mimic NC (5'-UUC UCCGAACGUGUCACGUTT-3'), miR-195 inhibitor (5'-GCC AAUAUUUCUGUGCUGCUA-3') and inhibitor-NC (5'-CAA UAUUUCUGUGCUGCUAUU-3' all were from Shanghai GenePharma Co., Ltd. Transfection into OVCAR-3 cells were performed using Lipofectamine ${ }^{\circledR} 2000$ Transfection reagent (Invitrogen; Thermo Fisher Scientific, Inc.), according to the manufacturer's instructions.

To generate OVCAR-3 cells overexpressing CDC42 or CCND1,pcDNA 3.1-CDC42 and pcDNA 3.1-CCND1 (Generay Biotech Co., Ltd.) were cloned into a pcDNA 3.1 vector (Promega Corporation) and transfected into OVCAR-3 cells at $10 \mathrm{nM}$ concentration. Lipofectamine ${ }^{\circledR} 2000$ Transfection reagent (Invitrogen; Thermo Fisher Scientific, Inc.) was used to mediate the transfection. The empty vector was used as the control. To knockdown CDC42 or CCND1 expression in OVCAR-3 cells, HS_CDC42 small interfering (si)RNA (5'-CATCAGATTTTGAAAATATTTAA-3'), HS_CCND1 siRNA (5'-GCCACAGATGTGAAGTTCA-3') and NC siRNA (5'-AATTCTCCGAACGTGTCACGT-3'), provided by GeneCopoeia, Inc., were transfected into OVCAR-3 cells using Lipofectamine RNAiMAX (Invitrogen; Thermo Fisher Scientific, Inc.) at $50 \mathrm{nM}$, according to the manufacturer's instructions.

Cell proliferation evaluation. Cell proliferation was evaluated using a Bromodeoxyuridine (BrdU) incorporation assay and a colony formation assay. The BrdU incorporation assay was performed at $24 \mathrm{~h}$ following transfection of OVCAR-3 cells, as previous reported (19). Colony formation was performed at $48 \mathrm{~h}$ after transfection, as previous reported (20).
Cell cycle and cell apoptosis assay. After transfection for $48 \mathrm{~h}$, cell cycle and apoptosis were detected using flow cytometry (21). The cell cycle was detected using $20 \mu \mathrm{g} / \mathrm{ml}$ PI (Becton, Dickinson and Company) at $37^{\circ} \mathrm{C}$ for $30 \mathrm{~min}$ in dark. Cell apoptosis was detected using a BD apoptosis assay kit (Becton, Dickinson and Company) according to the manufacturer's instruction. A flow cytometer (Flow Sight; Merck $\mathrm{KGaA}$ ) was used to assess cell cycle distribution and cell apoptosis. Cell cycle was analyzed using a FacsCalibur system (Cytek Development Inc.). FlowJo software (v10.0.7; Becton, Dickinson and Company) was used to analyze the percentage of apoptotic cells.

Cell migration and invasion assay. A total of $24 \mathrm{~h}$ after transfection, cell migration was assessed using the wound healing assay. Cells were scrapped vertically using pipette head tips. Then, cell were washed with PBS and cultured with serum-free medium at $37^{\circ} \mathrm{C}$ for $24 \mathrm{~h}$.

A total of $48 \mathrm{~h}$ after transfection, cell invasion was measured using a Transwell invasion assay, as described in a previous study (22). Wound migration were observed under a light microscope at $\mathrm{x} 40$ magnification and cell invasion were observed under a light microscope at x200 magnification. Migrated cell and invaded cell were analyzed using ImageJ software (v1.8.0, National Institutes of Health).

Statistical analysis. SPSS 15.0 software (SPSS, Inc.) was used for statistical analyses. Each experiment was repeated three times. Data are presented as the mean \pm standard deviation. One-way ANOVA followed by Tukey's multiple comparison test was used to compare the data between groups. Correlation between miR-195 and CDC42 or CCND1 was analyzed using Pearson's correlation coefficient. Expression levels of miR-195, CDC42 and CCND1 in healthy tissues and EOC tissues were compared using a paired t-test. $\mathrm{P}<0.05$ was considered to indicate a statistically significant difference.

\section{Results}

Expression levels of miR-195, CDC42 and CCND1 in EOC tissues and cells. RT-qPCR results demonstrated that miR-195 was significantly downregulated in EOC tissues (Fig. 1A). Moreover, western blotting and immunohistochemistry results indicated that CDC42 and CCND1 were significantly upregulated in EOC tissues (Fig. 1B and C). It was identified that the downregulation of miR-195 or increased expression levels of CDC42 and CCND1 were associated with a reduced degree of differentiation, advanced clinical TNM stage, higher serum CA125 content and advanced FIGO staging (Table I).

RT-qPCR results suggested that miR-195 was downregulated in EOC tissues, while western blotting results identified that CDC42 and CCND1 were upregulated in various EOC cell lines, including OVCA420, OVCAR-3, A2780 and SKOV3 cells. Additionally, the lowest expression of miR-195 and the highest expression levels of CDC42 and CCND1 occurred in OVCAR-3 cells (Fig. 1D and E). Thus, subsequent experiments were performed in OVCAR-3 cells.

miR-195 could regulate the expression levels of CDC42 and $C C N D 1$. It was found that the miR-195 mRNA expression was 
Table I. Associations of miR-195, CDC42 and CCND1 expression levels with the clinicopathological features in 78 patients with epithelial ovarian cancer.

\begin{tabular}{|c|c|c|c|c|c|c|c|}
\hline $\begin{array}{l}\text { Clinicopathologic } \\
\text { parameters }\end{array}$ & Number & $\begin{array}{l}\text { miR-195 } \\
\text { expression }\end{array}$ & P-value & $\begin{array}{c}\text { CDC42 } \\
\text { expression }\end{array}$ & $\mathrm{P}$-value & $\begin{array}{l}\text { CCND1 } \\
\text { expression }\end{array}$ & P-value \\
\hline \multicolumn{8}{|l|}{ Age, years } \\
\hline $40-49$ & 38 & $0.46 \pm 0.09$ & \multirow[t]{2}{*}{0.925} & $1.78 \pm 0.18$ & \multirow[t]{2}{*}{0.738} & $1.62 \pm 0.17$ & \multirow[t]{2}{*}{0.622} \\
\hline $50-60$ & 40 & $0.44 \pm 0.07$ & & $1.81 \pm 0.24$ & & $1.58 \pm 0.14$ & \\
\hline \multicolumn{8}{|c|}{ Differentiation degree } \\
\hline Low & 26 & $0.34 \pm 0.06$ & \multirow[t]{3}{*}{$<0.01$} & $1.88 \pm 0.26$ & \multirow[t]{3}{*}{$<0.01$} & $1.74 \pm 0.16$ & \multirow[t]{3}{*}{$<0.01$} \\
\hline Middle & 23 & $0.41 \pm 0.08$ & & $1.79 \pm 0.18$ & & $1.63 \pm 0.15$ & \\
\hline High & 29 & $0.55 \pm 0.10$ & & $1.62 \pm 0.13$ & & $1.52 \pm 0.13$ & \\
\hline \multicolumn{8}{|l|}{ TNM stage } \\
\hline I & 23 & $0.61 \pm 0.12$ & \multirow[t]{3}{*}{$<0.01$} & $1.63 \pm 0.14$ & \multirow[t]{3}{*}{$<0.01$} & $1.53 \pm 0.13$ & \multirow[t]{3}{*}{$<0.01$} \\
\hline II & 36 & $0.54 \pm 0.10$ & & $1.76 \pm 0.16$ & & $1.66 \pm 0.16$ & \\
\hline III-IV & 19 & $0.38 \pm 0.07$ & & $1.92 \pm 0.28$ & & $1.78 \pm 0.17$ & \\
\hline \multicolumn{8}{|l|}{$\begin{array}{l}\text { Serum CA125 } \\
\text { content }(\mathrm{U} / \mathrm{ml})\end{array}$} \\
\hline$>83$ & 53 & $0.37 \pm 0.07$ & \multirow[t]{2}{*}{0.007} & $1.86 \pm 0.25$ & \multirow[t]{2}{*}{0.003} & $1.77 \pm 0.15$ & \multirow[t]{2}{*}{0.004} \\
\hline$<83$ & 25 & $0.63 \pm 0.13$ & & $1.58 \pm 0.11$ & & $1.52 \pm 0.12$ & \\
\hline \multicolumn{8}{|l|}{ FIGO staging } \\
\hline I & 23 & $0.61 \pm 0.12$ & \multirow[t]{4}{*}{$<0.01$} & $1.63 \pm 0.14$ & \multirow[t]{4}{*}{$<0.01$} & $1.53 \pm 0.13$ & \multirow[t]{4}{*}{$<0.01$} \\
\hline II & 35 & $0.53 \pm 0.09$ & & $1.77 \pm 0.15$ & & $1.64 \pm 0.15$ & \\
\hline III & 15 & $0.42 \pm 0.08$ & & $1.85 \pm 0.15$ & & $1.76 \pm 0.16$ & \\
\hline IV & 5 & $0.37 \pm 0.08$ & & $2.02 \pm 0.20$ & & $1.95 \pm 0.18$ & \\
\hline
\end{tabular}

Data are presented as the mean \pm SD. FIGO, International Federation of Gynecology and Obstetrics.
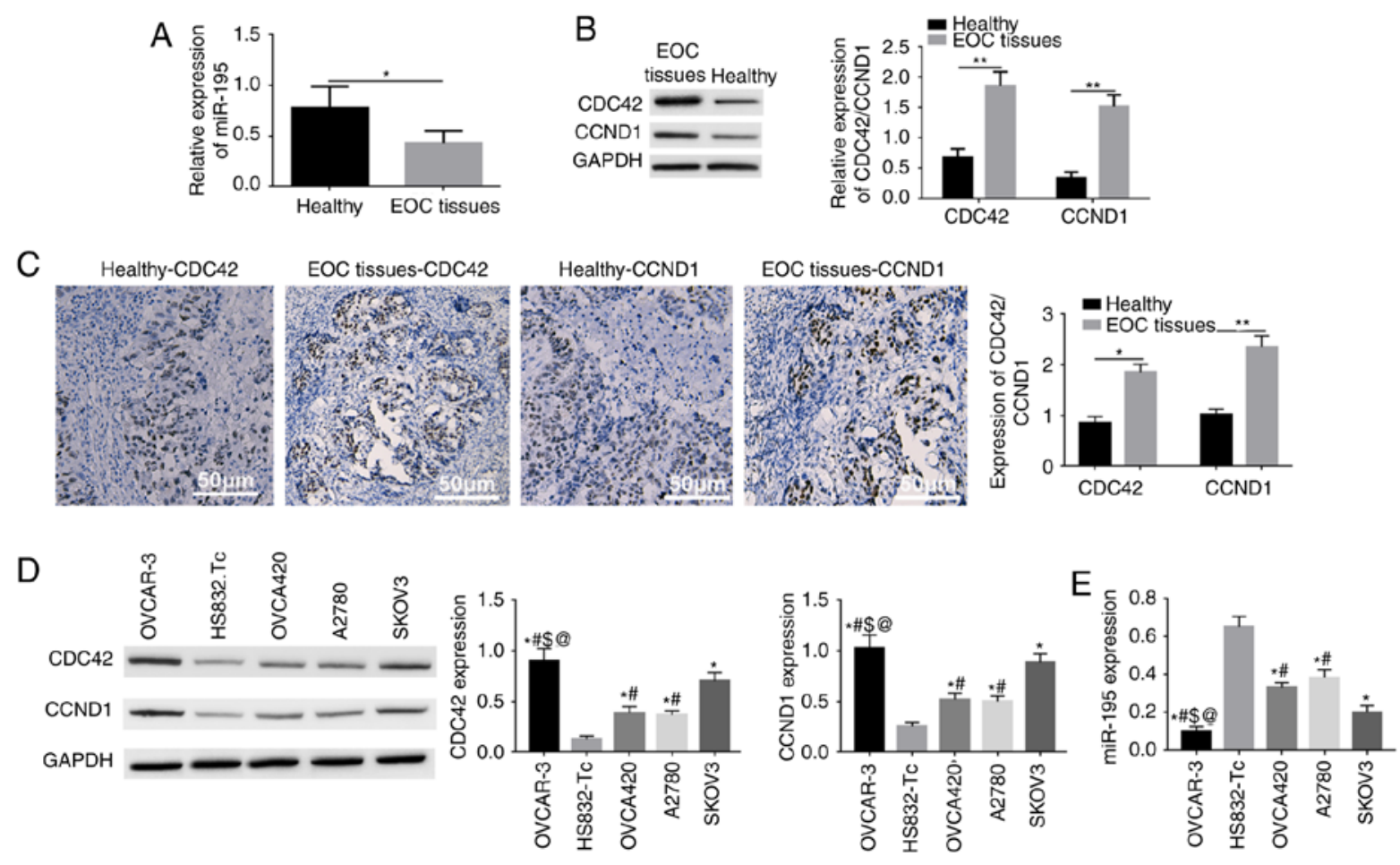

Figure 1. miR-195 is downregulated, while CDC42 and CCND1 are upregulated in human EOC tissues and cells. (A) mRNA expression of miR-195 in human EOC tissues. (B) Protein expression levels of CDC42 and CCND1 in human EOC tissues. (C) Immunohistochemical staining of CDC42 and CCND1 in human EOC tissues. Scale bar, $100 \mu \mathrm{m}$. (D) Protein expression levels of CDC42 and CCND1 in human EOC cells. (E) mRNA expression of miR-195 in diverse human EOC cells. Data in Fig. 1A-C were analyzed using a paired t-test. ${ }^{*} \mathrm{P}<0.05,{ }^{* *} \mathrm{P}<0.01$ vs. healthy tissues. Data in the Fig. $1 \mathrm{D}$ were analyzed using a one-way ANOVA. ${ }^{*} \mathrm{P}<0.05$ vs. HS832-Tc cells; ${ }^{*} \mathrm{P}<0.05$ vs. SKOV3 cells; ${ }^{~} \mathrm{P}<0.05$ vs. OVCA420 cells; ${ }^{\circ} \mathrm{P}<0.05$ vs. A2780 cells. EOC, epithelial ovarian carcinoma; miR, microRNA; CDC42, Cell division cycle 42; CCND1, cyclin D1. 
A

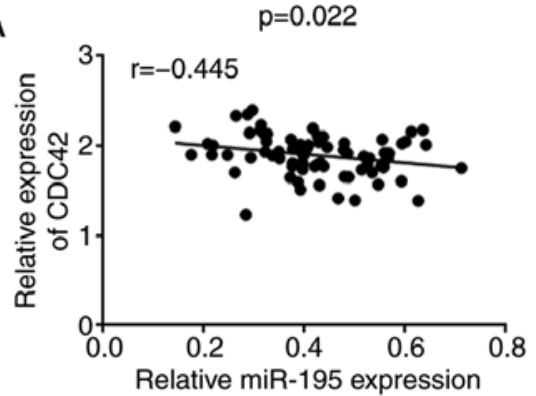

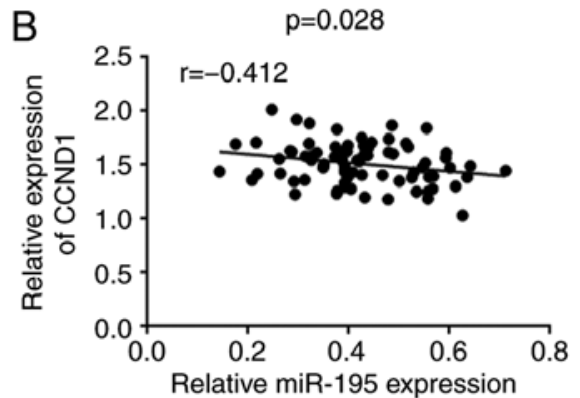
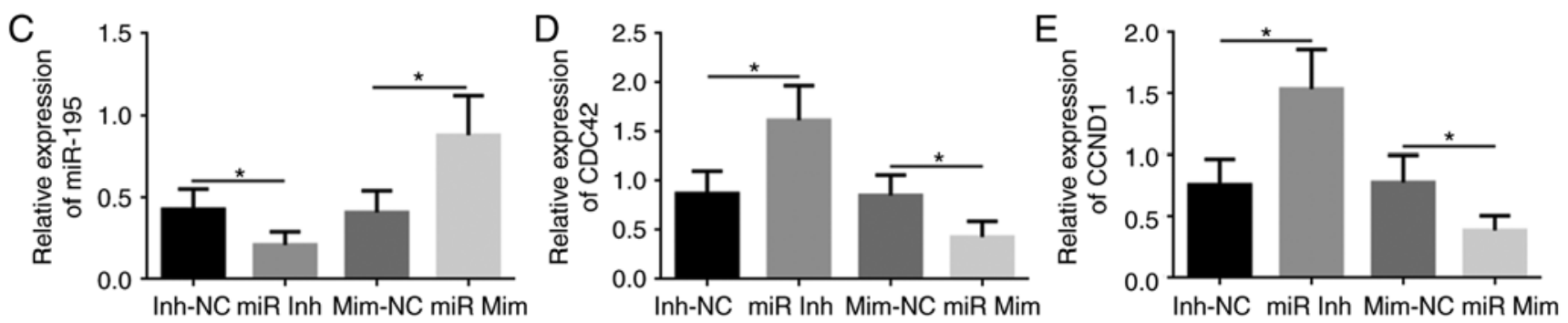

Figure 2. miR-195 can regulate CDC42 and CCND1 expression levels. Correlation between miR-195 and (A) CDC42 and (B) CCND1 expression levels in human epithelial ovarian carcinoma tissues were analyzed using Pearson's correlation coefficient. (C) mRNA expression of miR-195 in OVCAR-3 cells transfected with miR-195 mimic, mimic-NC, miR-195 inhibitor and inhibitor-NC. mRNA expression levels of (D) CDC42 and (E) CCND1 with overexpression or knockdown of miR-195 in OVCAR-3 cells. Data were analyzed using one-way ANOVA. "P<0.05. miR, miR-195; Mim, mimic; NC, negative control; Inh, inhibitor; CDC42, Cell division cycle 42; CCND1, cyclin D1.

negatively correlated with CDC42 and CCND1 protein expression levels in human EOC tissues (Fig. 2A and B). Transfection of the miR-195 mimic led to significantly increased expression of miR-195 in OVCAR-3 cells compared with the mimic-NC group, while the miR-195 inhibitor significantly decreased miR-195 expression compared with the miR-195 inhibitor-NC group (Fig. 2C). miR-195 knockdown resulted in the upregulation of CDC42 and CCND1, while miR-195 overexpression caused downregulation of CDC42 and CCND1 in OVCAR-3 cells (Fig. 2D and E).

miR-195 represses cell proliferation by inhibiting CDC42 and $C C N D 1$ expression levels in OVCAR-3 cells in vitro. In order to investigate whether the effect of miR-195 in cell proliferation and apoptosis was CDC42/CCND1 dependent, OVCAR-3 cells overexpressing CDC42 or CCND1 and knocking down CDC42 or CCND1 in OVCAR-3 cells were generated (Fig. S1). RT-qPCR results indicated that knockdown of miR-195 significantly promoted CDC42 and CCND1 expression levels, but transfection with CDC42 or CCND1 siRNA reversed this trend, and induced downregulation of CDC42 or CCND1 in OVCAR-3 cells (Fig. 3A and B). By contrast, overexpression of miR-195 significantly reduced CDC42 and CCND1 expression levels, but transfection with a CDC42 or CCND1 overexpression vector resulted in upregulation of CDC42 and CCND1 (Fig. 3C and D).

Knockdown of miR-195 resulted in enhanced cell proliferation, with significantly increased percentages of BrdU-positive cells and clone formation; however, this enhanced cell proliferative ability was significantly reversed after CDC42 or CCND1 siRNA co-transfection (Fig. 3E and F). Overexpression of miR-195 and co-transfection with miR-195 mimic and the CDC42 or CCND1 overexpression vector demonstrated opposite outcomes to treatment with miR-195 inhibitor and CDC42 or CCND1 siRNAs (Fig. 3E and F). These findings indicated that miR-195 repressed cell proliferation by inhibiting CDC42 and CCND1 expression levels in OVCAR-3 cells in vitro.

miR-195 inhibits cell cycle entry and promotes apoptosis in OVCAR-3 cells by downregulating CDC42 and CCND1 expression levels in vitro. Flow cytometry with PI staining identified that the miR-195 inhibitor increased cell cycle entry, which arrested OVCAR-3 cells at $S$ and $G_{2}$ phases, with significantly fewer EOC cells appearing in $\mathrm{G}_{1}$ phase (Fig. 4). However, following co-transfection with CDC42 or CCND1 siRNA, cell cycle entry was inhibited, with reduced $S$ and $G_{2}$ phase cells and increased $\mathrm{G}_{1}$ phase OVCAR-3 cells compared with cells transfected with NC siRNA. Additionally, overexpression of miR-195 restrained OVCAR-3 cell cycle entry, while overexpression of CDC42 or CCND1 reversed this pattern and facilitated cell cycle entry (Fig. 4).

Flow cytometry with Annexin V-FITC/PI staining suggested that knockdown of miR-195 reduced apoptosis of OVCAR-3 cells in vitro compared with the miR-195 inhibitor-NC group. Conversely, following co-transfection with CDC42 or CCND1 siRNA, the apoptotic rate was significantly increased compared with the NC siRNA (Fig. 5). Moreover, transfection with miR-195 mimic and overexpression vectors of CDC42 or CCND1 exerted the opposite effects to the miR-195 inhibitor and CDC42 or CCND1 siRNAs (Fig. 5).

miR-195 suppresses migration and invasion in OVCAR-3 cells by inhibiting CDC42 and CCND1 expression levels in vitro. The wound healing assay results demonstrated that knockdown of miR-195 caused increased OVCAR-3 cell migration, compared with the miR-195 inhibitor-NC group. Furthermore, OVCAR-3 cells migrated toward the wound more slowly following co-transfection with CDC42 siRNA compared 

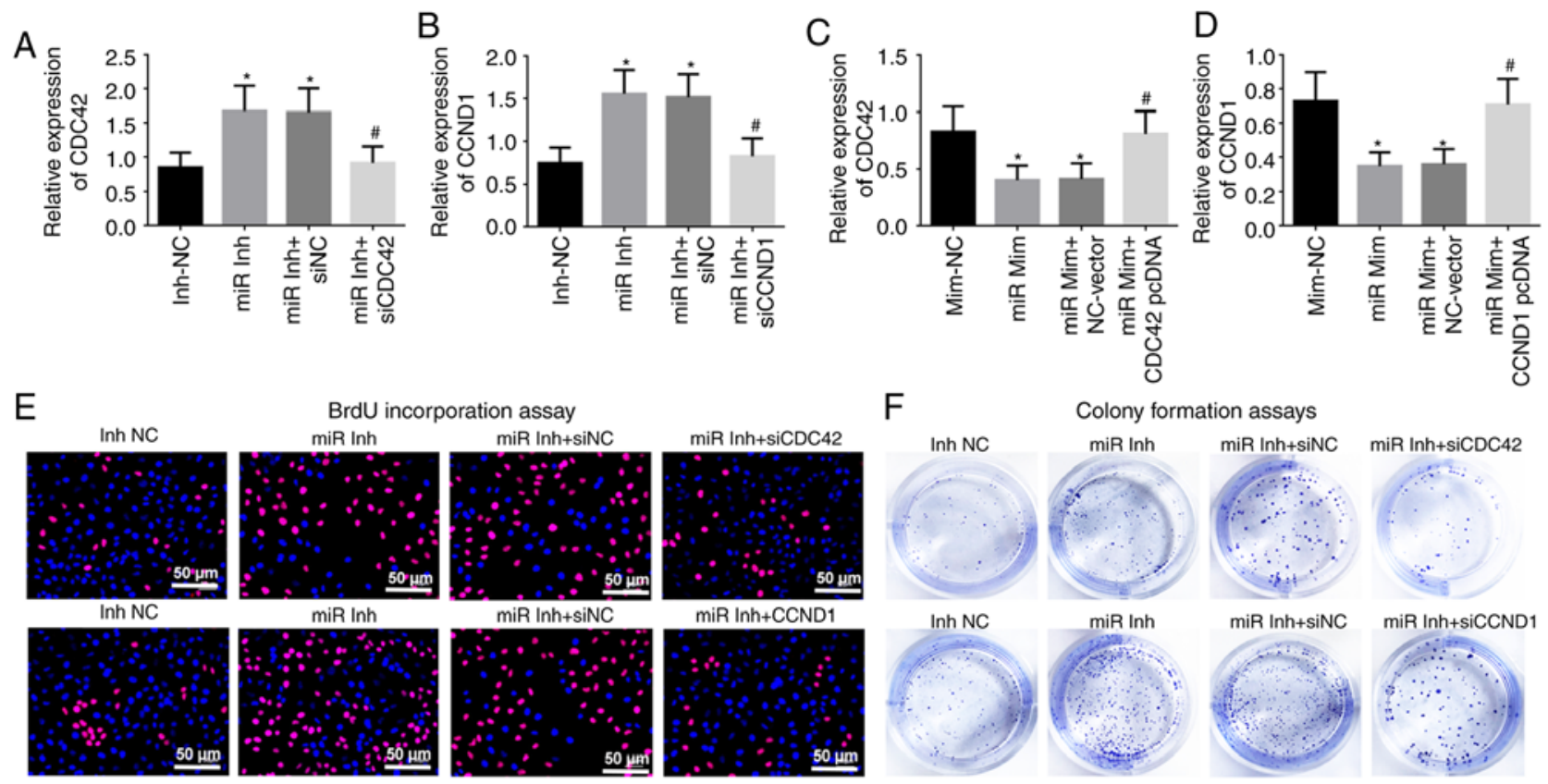

F

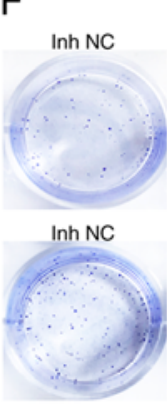

Colony formation assays
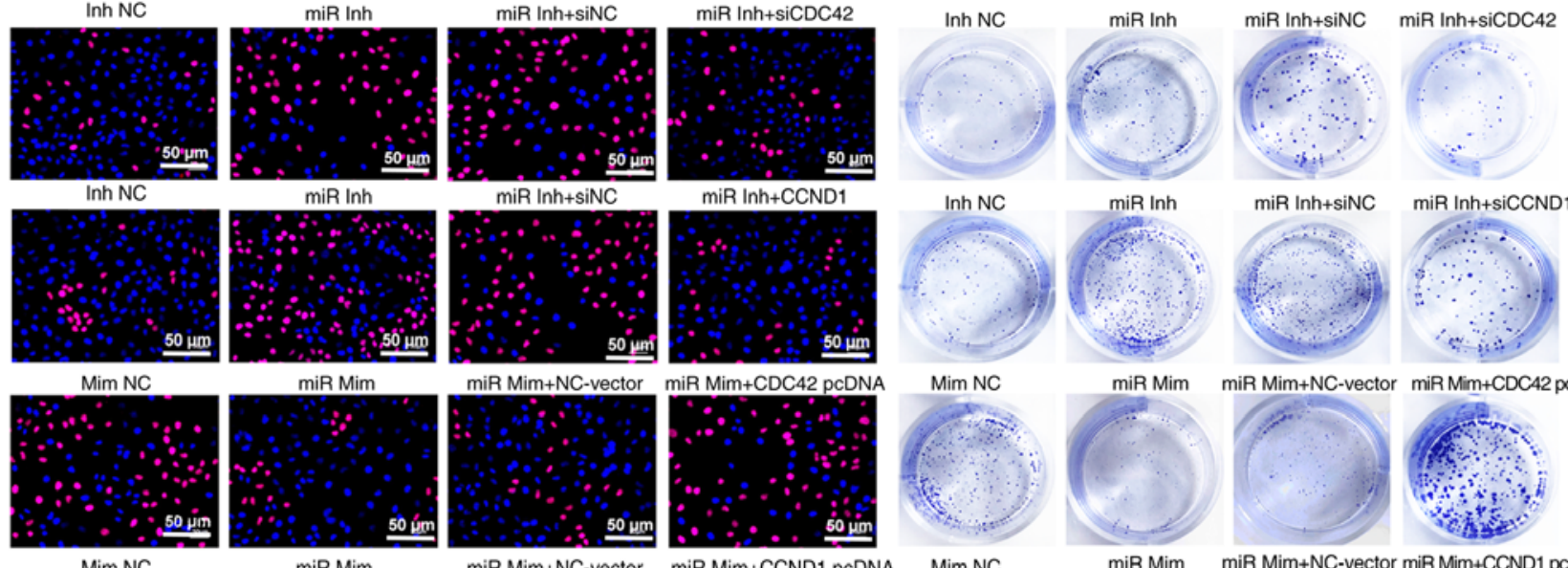

miR Inh

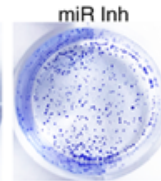

$\mathrm{miR}$ Inh+siNC $\quad \mathrm{miR}$ Inh+siCCND1

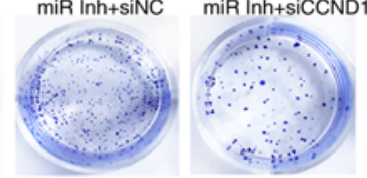

miR Mim

miR Mim+NC-vector miRMim+CDC42 pcDNA
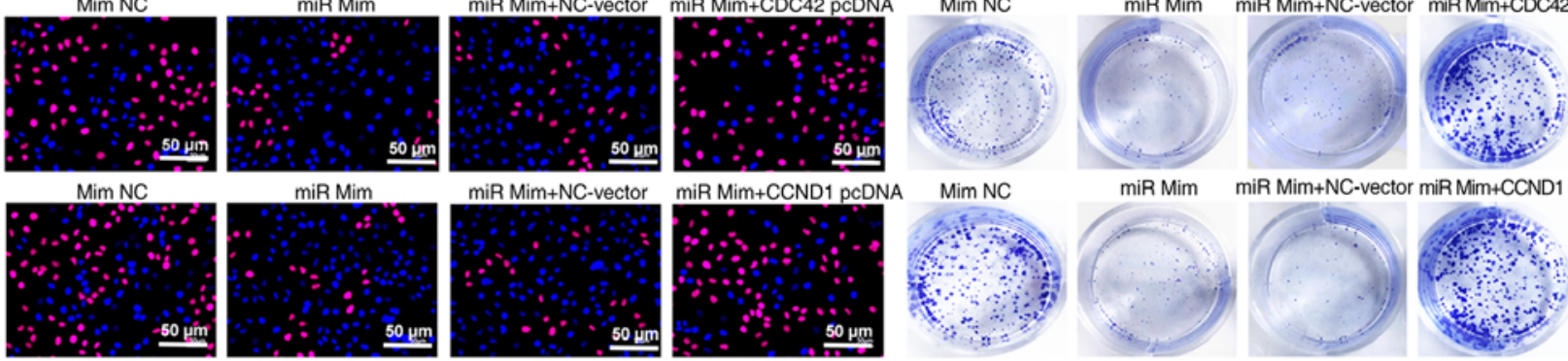

miR Mim+NC-vector miR Mim+CCND1 pcDNA
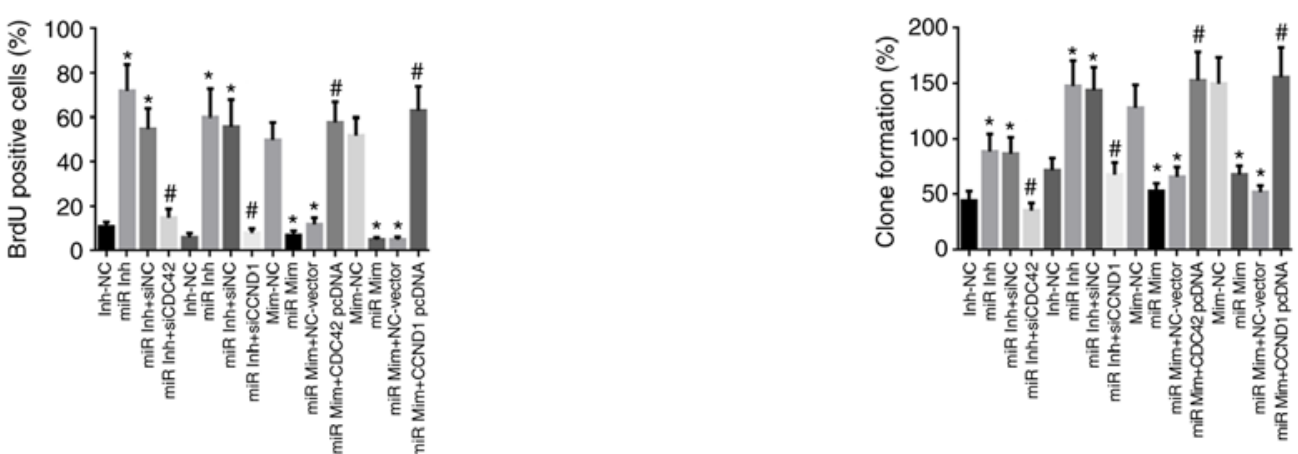

Figure 3. miR-195 inhibits cell proliferation by reducing CDC42 and CCND1 expression levels in OVCAR-3 cells in vitro. mRNA expression levels of (A) CDC42 and (B) CCND1 in OVCAR-3 cells transfected with miR-195 inhibitor, inhibitor-NC, miR-195 inhibitor + NC and miR-195 inhibitor + CDC42 or CCND1 siRNAs. mRNA expression levels of (C) CDC42 and (D) CCND1 in OVCAR-3 cells transfected with miR-195 mimic, mimic-NC, miR-195 mimic + NC-vector and miR-195 mimic + CDC42 or CCND1 pcDNA. (E) Cell proliferation was assessed using BrdU immunostaining at $24 \mathrm{~h}$ after transfection. Red, OVCAR-3 cells labeled with BrdU; blue, nuclei counterstained by BrdU. Scale bar, $50 \mu \mathrm{m}$. (F) Evaluation of cell proliferation via colony formation assays at $48 \mathrm{~h}$ after transfection. Data were analyzed using one-way ANOVA. "P<0.05 vs. Inh-NC or Mim-NC groups; ${ }^{*} \mathrm{P}<0.05 \mathrm{vs}$. miR Inh-siNC or miR Mim + NC-Vector groups. BrdU, 5-bromo-2-deoxyuridine; miR, miR-195; Inh, inhibitor; NC, negative control, siRNA, short interfering RNA; Mim, mimic; CDC42, Cell division cycle 42; CCND1, cyclin D1.

with cells transfected with the NC siRNA. The migration of OVCAR-3 cells was significantly weakened after overexpression of miR-195 and reversed following transfection with the CDC42 or CCND1 overexpression vector (Fig. 6A and B).

The Transwell invasion assay identified a significant increase in the number of invading OVCAR-3 cells in the miR-195 inhibitor group compared with the miR-195 inhibitor-NC group; however, the number of invading OVCAR-3 cells was reduced following co-transfection with CDC42 or CCND1 siRNA compared with NC siRNA (Fig. 6C). In addition, the miR-195 mimic induced a significant decrease in invading cells compared with the $\mathrm{NC}$ mimic, while a higher number of invading OVCAR-3 cells was observed in the group co-transfected with the CDC42 or CCND1 overexpression vector compared with the NC-vector group (Fig. 6B).

\section{Discussion}

EOC is the most frequent histopathological type of OC, with a 5-year survival rate of $\sim 30 \%$ and the highest mortality rate 


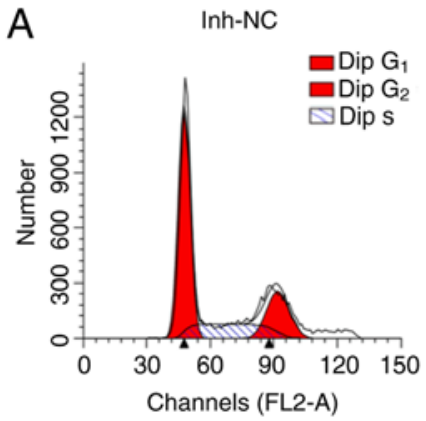

Inh-NC

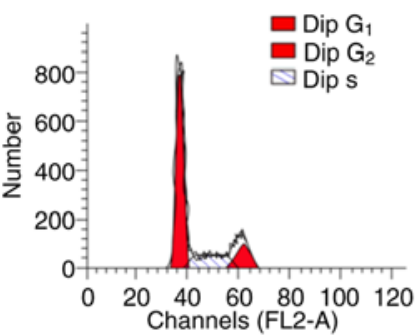

Mim NC

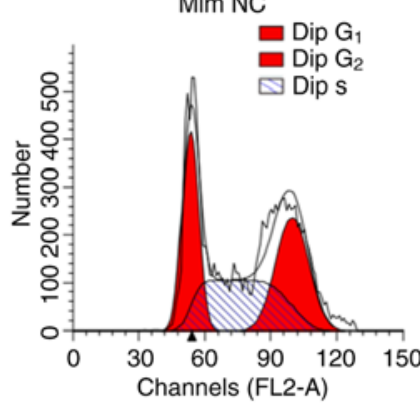

$\operatorname{Mim}$ NC

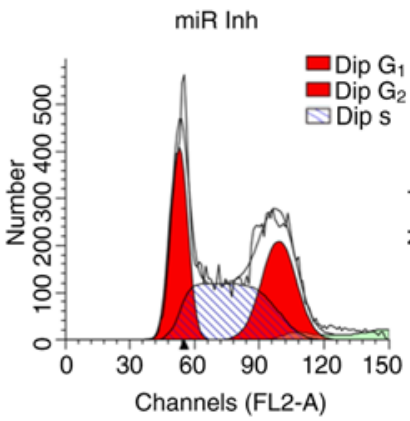

$\mathrm{miR}$ Inh
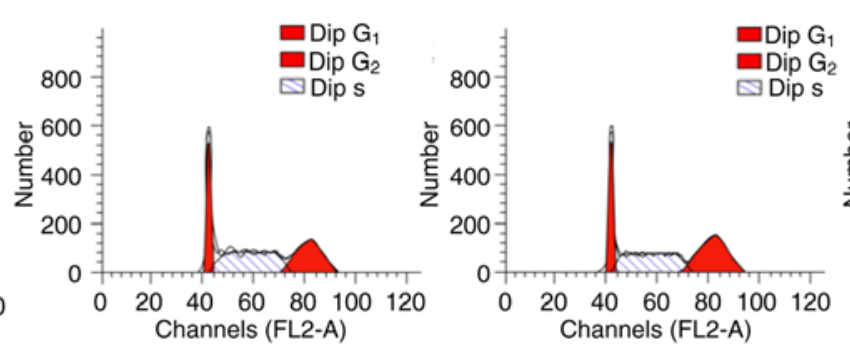

$\operatorname{miR} \operatorname{Inh}+\operatorname{siNC}$

miR Inh+siCCNDC42

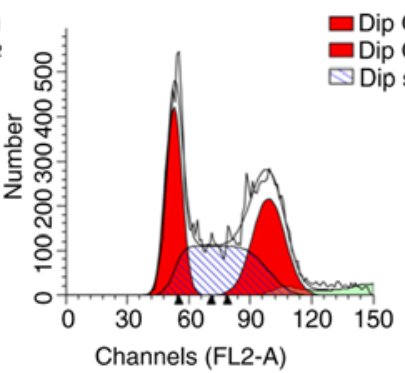

$\mathrm{miR}$ Inh+siNC

miR Mim+NC-vector
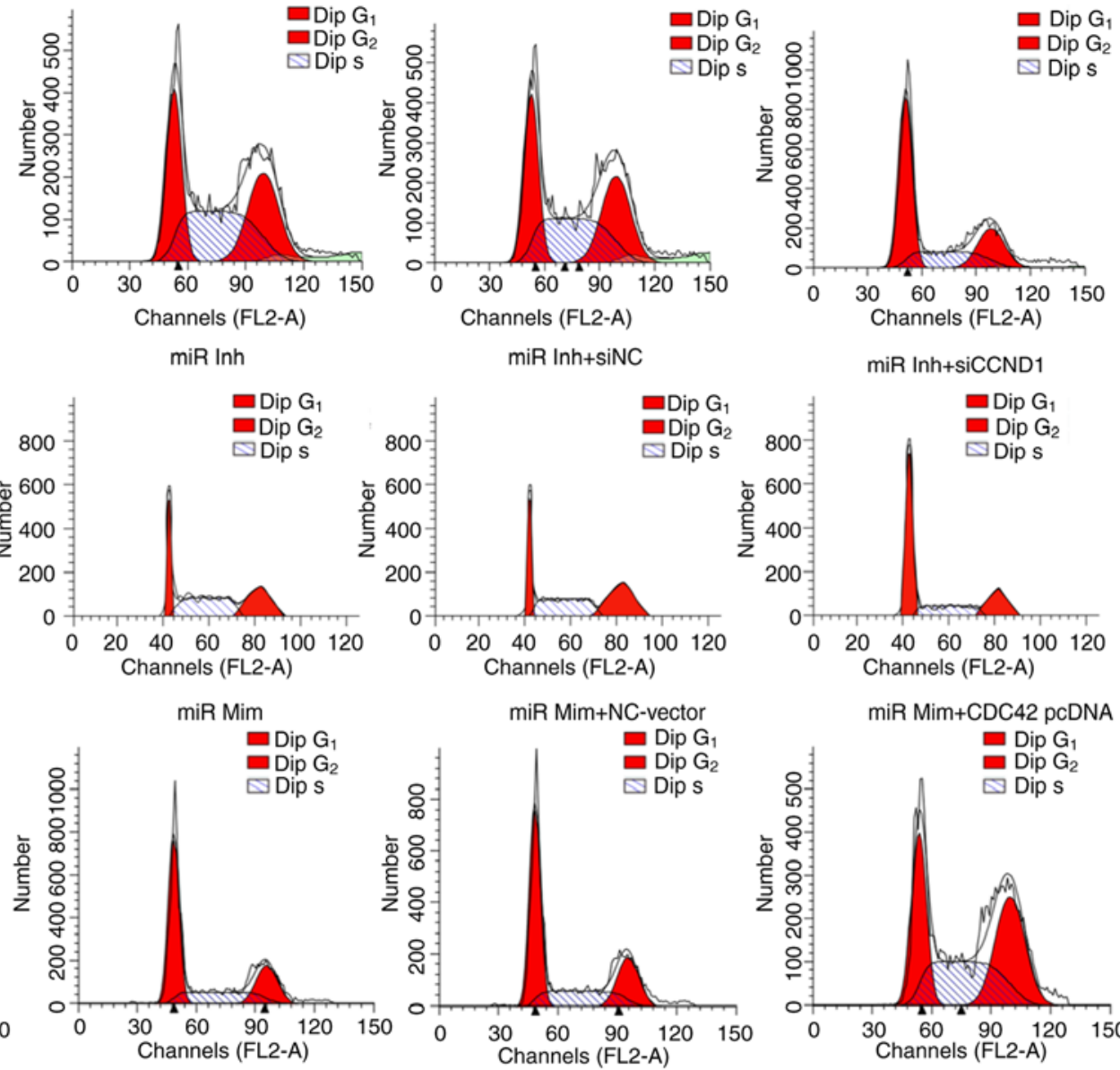

miR Inh+siCCND1
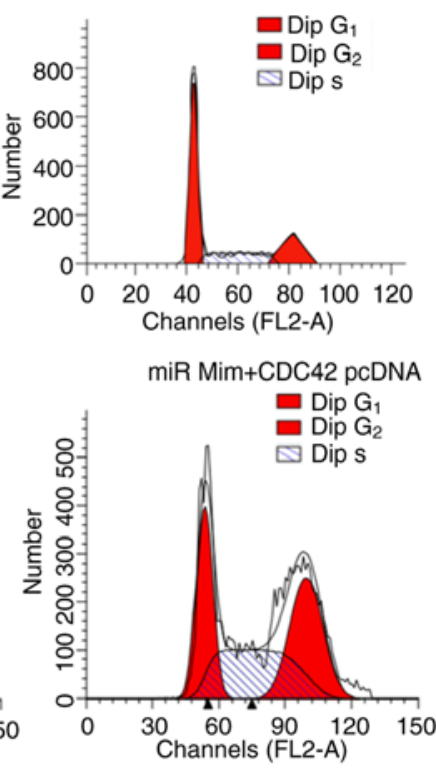

miR Mim

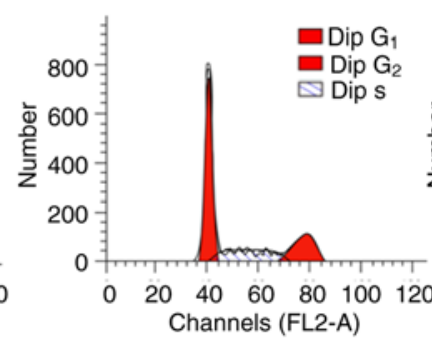

miR Mim+NC-vector
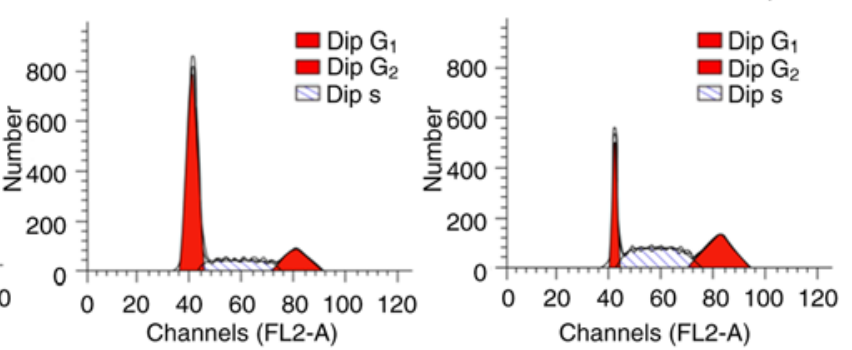

B

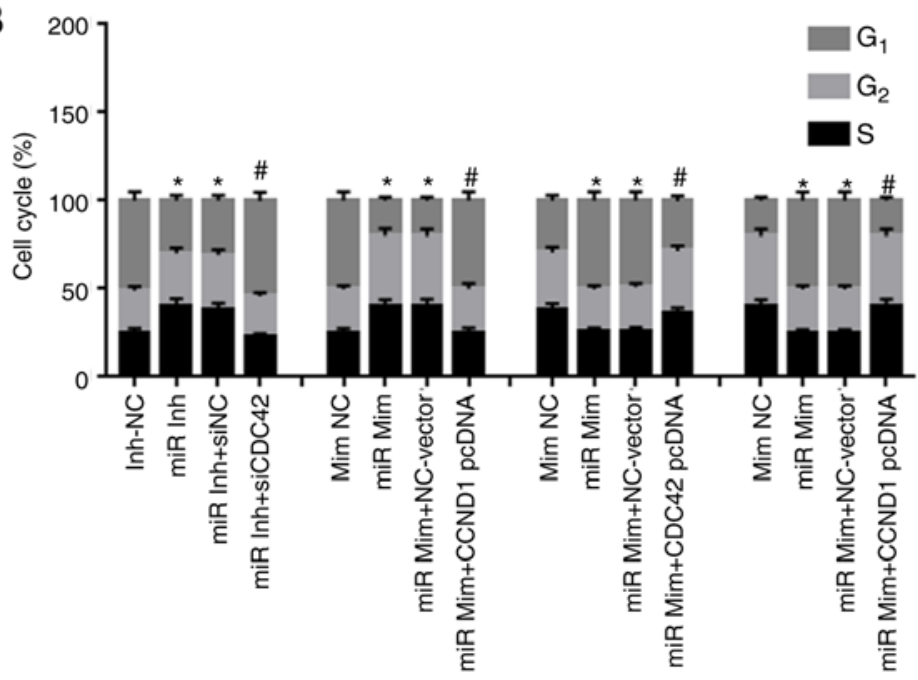

Figure 4. miR-195 inhibits cell cycle entry in OVCAR-3 cells by downregulating CDC42 and CCND1 expression levels in vitro. (A) Effects of miR-195, CDC42 and CCND1 on the percentage of PI-stained OVCAR-3 cells at $\mathrm{G}_{1}, \mathrm{~S}$ and $\mathrm{G}_{2}$ phases. (B) Cell cycle of each group. Data were analyzed via one-way ANOVA. "P<0.05 vs. Inh-NC or Mim-NC groups; ${ }^{*} \mathrm{P}<0.05$ vs. miR Inh-siNC or miR Mim + NC-Vector groups. miR, miR-195; Inh, inhibitor; NC, negative control, siRNA, short interfering RNA; Mim, mimic; CDC42, Cell division cycle 42; CCND1, cyclin D1. 
A
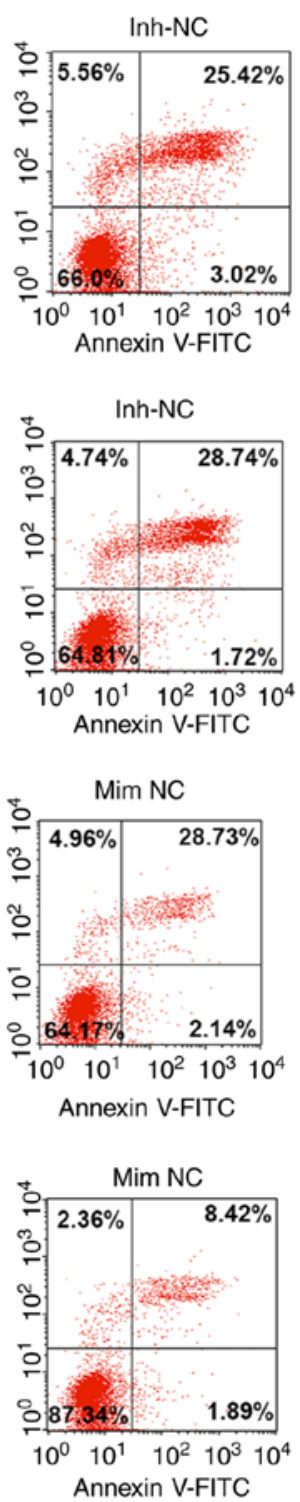
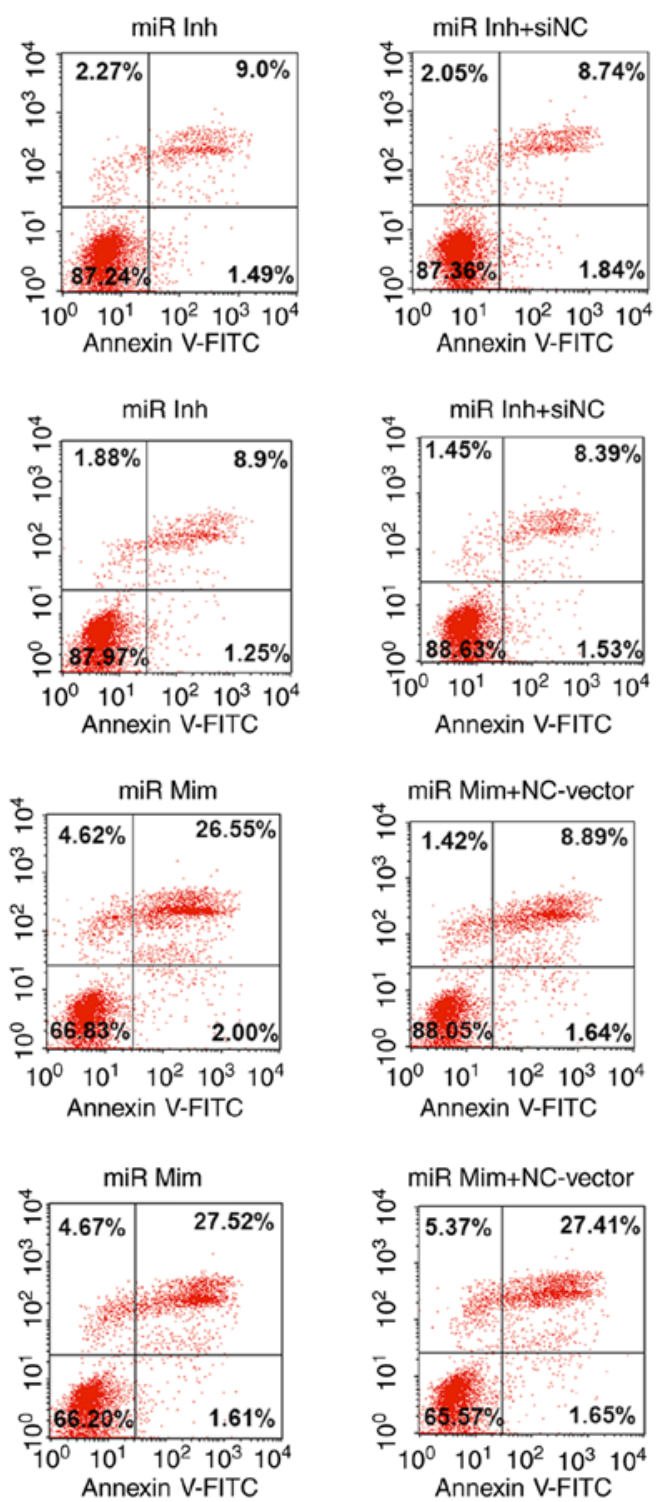

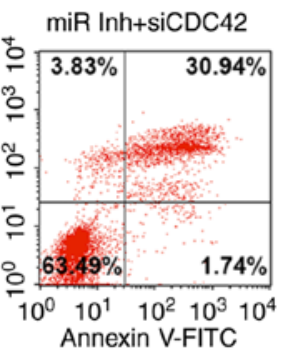

If $m i R$ Inh+siCCND1

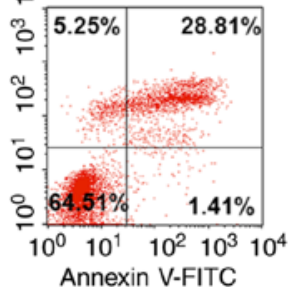

I $\mathrm{miR}$ Mim+CDC42 pcDNA
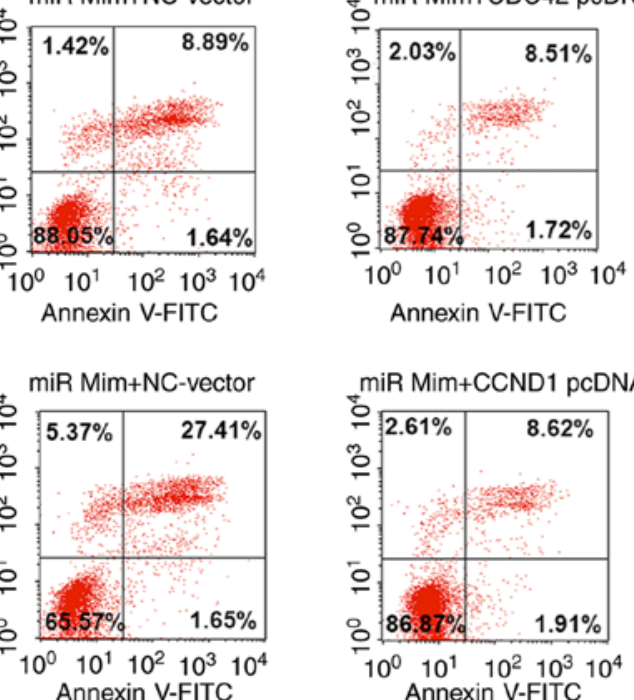

B

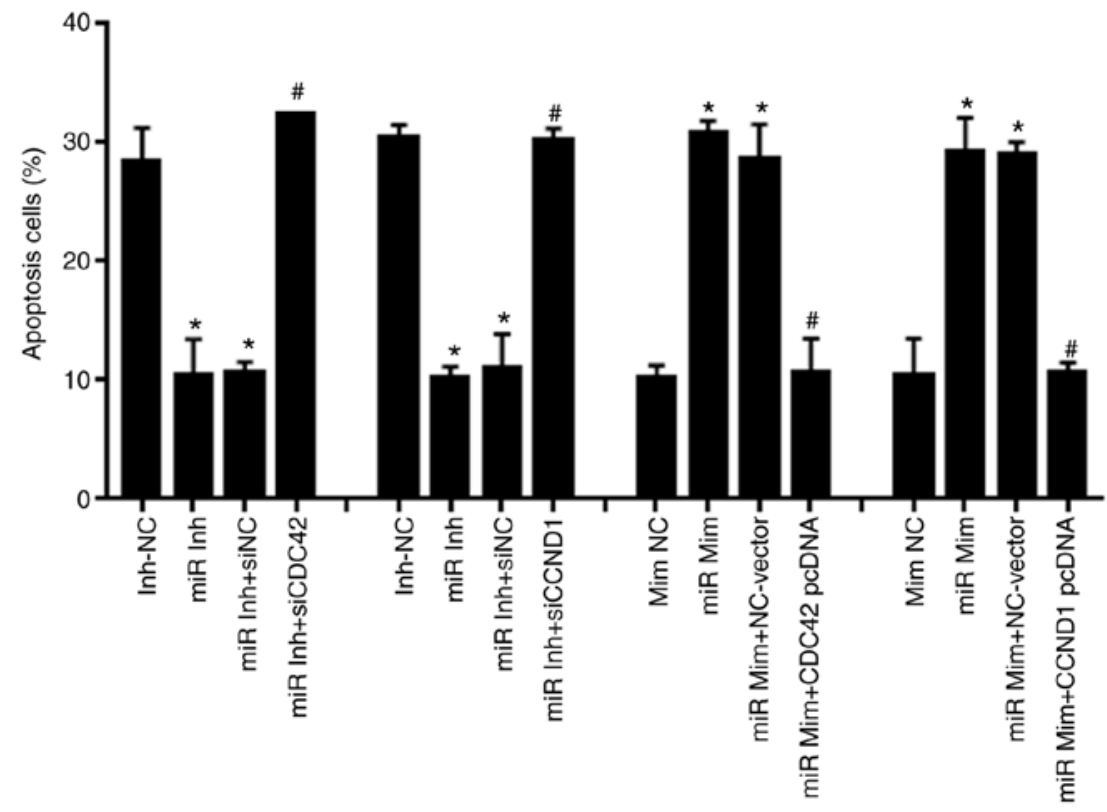

Figure 5. miR-195 promotes apoptosis in OVCAR-3 cells by downregulating CDC42 and CCND1 expression levels in vitro. (A) Effects of miR-195, CDC42 and CCND1 on cell apoptosis. (B) Apoptotic cells in each group. Data were analyzed using one-way ANOVA. ${ }^{*} \mathrm{P}<0.05$ vs. Inh-NC or Mim-NC groups; ${ }^{\text {P }}<0.05$ vs. miR Inh-siNC or miR Mim + NC-Vector groups. miR, miR-195; Inh, inhibitor; NC, negative control, siRNA, short interfering RNA; Mim, mimic; CDC42, Cell division cycle 42; CCND1, cyclin D1. 

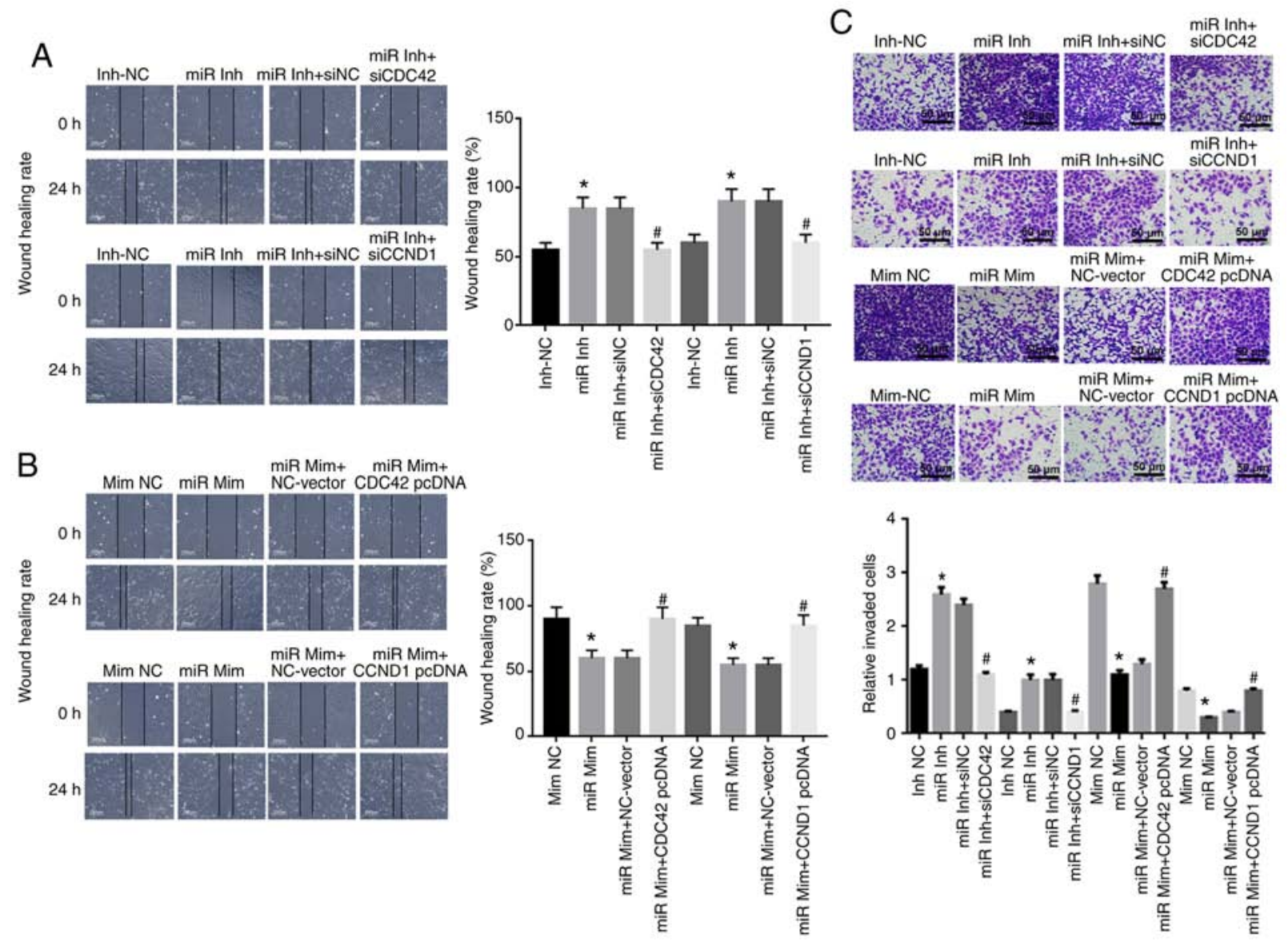

Figure 6. miR-195 suppresses cell migration and invasion in OVCAR-3 cells by inhibiting CDC42 and CCND1 expression levels in vitro. Effects of miR-195 (A) inhibitor or (B) mimic, CDC42 and CCND1 on OVCAR-3 cell migration using wound healing assay at 0 and $24 \mathrm{~h}$ after transfection. Scale bar, $200 \mu \mathrm{m}$. (C) Effects of miR-195, CDC42 and CCND1 on OVCAR-3 cell invasion via Transwell invasion assay at $48 \mathrm{~h}$ after transfection. Scale bar, $50 \mu \mathrm{m}$. Data were analyzed using one-way ANOVA. ${ }^{*} \mathrm{P}<0.05$ vs. Inh-NC or Mim-NC groups; ${ }^{~} \mathrm{P}<0.05$ vs. miR Inh-siNC or miR Mim $+\mathrm{NC}-\mathrm{Vector}$ groups. miR, miR-195; Inh, inhibitor; NC, negative control, siRNA, short interfering RNA; Mim, mimic; CDC42, Cell division cycle 42; CCND1, cyclin D1.

of all gynecological tumors worldwide (1). Thus, EOC is a serious threat to the lives of women. As EOC is difficult to diagnose at an early stage, there are limited treatment options and high rates of metastasis and recurrence following operative therapy $(7,8)$. Therefore, the identification of biological targets for the diagnosis and treatment of EOC is an urgent issue. In the present study, miR-195 expression was found to be downregulated in human EOC tissues and multifold cells, particularly in OVCAR-3 cells, compared with the corresponding control groups. Moreover, this downregulation of miR-195 was closely associated with reduced differentiation, higher clinical TNM stage and increased serum EOC marker/CA125 content. Thus, miR-195 may be a potential target of EOC.

Previous studies have reported that aberrant expression of miRNAs may be a marker of the development and progression of various tumors or cancer types, as they are associated with abnormal cell viability, proliferation, migration, invasion, apoptosis and differentiation (23-25). The present results suggested that miR-195 was downregulated in human EOC tissues and cells, which led to an increase in cell proliferation, cell cycle entry, migration and invasion, as well as a decrease in apoptosis of OVCAR-3 cells in vitro. Another published report regarding the role of miR-195 in OC indicated that miR-195 was downregulated in human OC serum samples, which resulted in an increase in cell proliferation and decreased apoptosis of human OVCAR-3 cells, which was in line with the current findings that knockdown of miR-195 induced an increase in cell proliferation and a decrease in cell apoptosis. Previous studies have also observed downregulation of miR-195 in other cancer types. For example, decreased miR-195 expression in hepatocellular carcinoma tissues significantly promotes proliferation, invasion and tumorigenesis (26). Moreover, miR-195 represses cell proliferation, migration and invasion, and accelerates apoptosis in glioma by decreasing spalt like transcription factor 4 protein expression (27). Downregulation of miR-195 in colon carcinoma tissues is also associated with increased cell proliferation, migration and invasion (28). Furthermore, miR-195 is downregulated in PTC tissues and cells, which facilitates cell cycle progression by inducing apoptosis (29). These previous findings were in accordance with the present results, and to the best of our knowledge, the current study was the first to demonstrate that miR-195 is downregulated in human EOC tissues and cells, and is associated with the CDC42/CCND1 pathway.

The present results suggested that the molecular mechanism of miR-195 in EOC was achieved via inhibition of the CDC42/CCND1 pathway. Previous studies have revealed that CDC42 and CCND1 are targets of miR-195 in ESCC and PTC, respectively $(15,16)$. Thus, the present study did not perform a luciferase reporter assay. The current results 
indicated that expression levels of CDC42 and CCND1 were negatively correlated with miR-195 in EOC tissues. In addition, CDC42 and CCND1 had a corresponding opposite effect following interference of miR-195 expression, which indirectly suggested that CDC42 and CCND1 are components of a downstream pathway of miR-195. In the present study, knockdown of miR-195 effectively increased cell proliferation and migration, decreased cell apoptosis and elevated CDC42 and CCND1 protein expression levels. A previous study identified that inhibition of CDC42 expression may be a key mechanism via which miR-18a impairs cancer cell proliferation (30). In the current study, overexpression of miR-195 significantly decreased cell proliferation and migration, promoted cell apoptosis and reduced CDC42 and CCND1 protein expression levels; these effects were reversed by CDC42 and CCND1 overexpression. The CDC42/CCND1 signaling pathway has been reported to promote cell migration and proliferation in endothelial cells. In addition, activation of the CDC42/CCND1 pathway could induce cell proliferation, migration and invasion to increase Ewing sarcoma metastasis (31). Overexpression of CDC42 and CCND1 has also been shown to cause increased cell migration, changes in cell morphology, $G_{1} / S$ phase cell cycle progression and decreased apoptosis in colorectal cancer cells (30). Collectively, these previous findings are in line with the present results, which found that overexpression of CDC42 and CCND1 was associated with enhanced cell proliferation, cell cycle progression, migration and invasion, as well as attenuated apoptosis in EOC cells. Therefore, miR-195 may suppress cell proliferation, migration and invasion in EOC via inhibition of the CDC42/CCND1 pathway.

There are limitations to the present study. First, a luciferase assay was not performed to directly confirm the relationship between miR-195 and CDC42. At present, evidence that CCND1 can act as a target of miR-195 has been reported in ESCC (15). The present results can only indirectly demonstrate that miR-195 could target CDC42 via assessing the reverse effect of CDC42 and CCND1 siRNA or CDC42 and CCND1 overexpression. Secondly, western blotting and RT-qPCR were not conducted to measure markers of migration, invasion and apoptosis in cells. Finally, the present study did not investigate AKT and its inhibitors on the effect of miR-195. A previous study revealed that miR-195 inhibited VEGFR2 and AKT signaling (12); therefore, further evidence regarding the underlying molecular mechanism of miR-195 is required.

In conclusion, the present study demonstrated that miR-195 was downregulated, while CDC42 and CCND1 were upregulated, in EOC tissues and cells, which led to increased malignancy of EOC. miR-195 can repress human EOC cell cycle entry, migration and invasion, and CDC42 and CCND1 serve as tumor promoters in EOC progression. Furthermore, it was identified that inhibition of the CDC42/CCND1 pathway via overexpression of miR-195 may be a possible mechanism for suppression of EOC progression. Thus, miR-195 may be an effective agent for EOC therapy and diagnosis via anti-proliferative, migration-inhibiting and pro-apoptotic effects via inhibition of the CDC42/CCND1 signaling pathway.

\section{Acknowledgements}

Not applicable.

\section{Funding}

No funding was received.

\section{Availability of data and materials}

The datasets used and/or analyzed during the present study are available from the corresponding author on reasonable request.

\section{Authors' contributions}

XH made substantial contributions to the conception and design of the study. QJ and JY performed the experiments. XS and $\mathrm{HG}$ participated in this experiment, and analyzed the data. JG contributed to acquisition of data. YG organized the figure and interpreted the data. $\mathrm{XH}$ reviewed and edited the manuscript. All authors read and approved the final manuscript.

\section{Ethics approval and consent to participate}

The present study was approved by the Clinical Ethical Committee of The Second Hospital of Shanxi Medical University, and written informed consent was obtained from all patients before the start of the study.

\section{Patient consent for publication}

Not applicable.

\section{Competing interests}

The authors declare that they have no competing interests.

\section{References}

1. Li X, Du N, Zhang Q, Li J, Chen X, Liu X, Hu Y, Qin W, Shen N $\mathrm{Xu}$ C, et al: MicroRNA-30d regulates cardiomyocyte pyroptosis by directly targeting foxo3a in diabetic cardiomyopathy. Cell Death Dis 5: e1479, 2014.

2. Parizadeh SM, Jafarzadeh-Esfehani R, Ghandehari M, Hasanzadeh M, Parizadeh SMR, Hassanian SM, Rezaei-Kalat A, Aghabozorgi AS, Rahimi-Kakhki R, Zargaran B, et al: Circulating and tissue microRNAs as biomarkers for ovarian cancer prognosis. Curr Drug Targets 20: 1447-1460, 2019.

3. Mülayim B, Gürakan H, Dagli V, Mülayim S, Aydin O and Akkaya H: Unaware of a giant serous cyst adenoma: A case report. Arch Gynecol Obstet 273: 381-383, 2006.

4. Menke K, Schwermer M, Falke K, Felenda J, Beckmann C, Stintzing F, Voigt A, Schramm A and Zuzak TJ: Taraxacum officinale extract induces antitumorigenic effects in ovarian carcinoma cell lines. Eur J Gynaecol Oncol 40: 106-112, 2019.

5. Ferlay J, Steliarova-Foucher E, Lortet-Tieulent J, Rosso S, Coebergh JW, Comber H, Forman D and Bray F: Cancer incidence and mortality patterns in Europe: Estimates for 40 countries in 2012. Eur J Cancer 49: 1374-1403, 2013.

6. Lim W and Song G: Discovery of prognostic factors for diagnosis and treatment of epithelial-derived ovarian cancer from laying hens. J Cancer Prev 18: 209-220, 2013.

7. Lheureux S, Gourley C, Vergote I and Oza AM: Epithelial ovarian cancer. Lancet 393: 1240-1253, 2019.

8. Motohara $\mathrm{T}$ and Katabuchi $\mathrm{H}$ : Ovarian cancer stemness: Biological and clinical implications for metastasis and chemotherapy resistance. Cancers (Basel) 11: 907, 2019.

9. Kagiya T: MicroRNAs: Potential biomarkers and therapeutic targets for alveolar bone loss in periodontal disease. Int J Mol Sci 17: 1317, 2016.

10. Piletič K and Kunej T: MicroRNA epigenetic signatures in human disease. Arch Toxicol 90: 2405-2419, 2016. 
11. Varamo C, Occelli M, Vivenza D, Merlano $M$ and Lo Nigro $C$ : MicroRNAs role as potential biomarkers and key regulators in melanoma. Genes Chromosomes Cancer 56: 3-10, 2017.

12. Chen J: miRNA-195 suppresses cell proliferation of ovarian cancer cell by regulating VEGFR 2 and AKT signaling pathways. Mol Med Rep 18: 1666-1673, 2018.

13. Pang H, Xu X, Dai L, Wang K and Yao X: MicroRNA-195 is associated with regulating the pathophysiologic process of human laryngeal squamous cell carcinoma. Mol Med Rep 17: 5283-5291, 2018.

14. Fu HL, Wu DP, Wang XF, Wang JG, Jiao F, Song LL, Xie H, Wen XY, Shan HS, Du YX and Zhao YP: Altered miRNA expression is associated with differentiation, invasion, and metastasis of esophageal squamous cell carcinoma (ESCC) in patients from Huaian, China. Cell Biochem Biophys 67: 657-668, 2013.

15. Sun N, Ye L, Chang T, Li X and Li X: microRNA-195-Cdc42 axis acts as a prognostic factor of esophageal squamous cell carcinoma. Int J Clin Exp Pathol 7: 6871-6879, 2014.

16. Yin Y, Hong S, Yu S, Huang Y, Chen S, Liu Y, Zhang Q, Li Y and Xiao H: MiR-195 inhibits tumor growth and metastasis in papillary thyroid carcinoma cell lines by targeting CCND1 and FGF2. Int J Endocrinol 2017: 6180425, 2017.

17. Pi J, Liu J, Zhuang T, Zhang L, Sun H, Chen X, Zhao Q, Kuang Y, Peng S, Zhou X, et al: Elevated Expression of miR302-367 in endothelial cells inhibits developmental angiogenesis via CDC42/CCND1 mediated signaling pathways. Theranostics 8: 1511-1526, 2018.

18. Livak KJ and Schmittgen TD: Analysis of relative gene expression data using real-time quantitative PCR and the 2(-Delta Delta C(T)) Method. Methods 25: 402-408, 2001.

19. Dong N, Xu B, Benya SR and Tang X. MiRNA-26b inhibits the proliferation, migration, and epithelial-mesenchymal transition of lens epithelial cells. Mol Cell Biochem 396: 229-238, 2014.

20. Dong M, Xie Y and Xu Y: miR-7-5p regulates the proliferation and migration of colorectal cancer cells by negatively regulating the expression of Krüppel-like factor 4. Oncol Lett 17: 3241-3246, 2019.

21. Fan X, Liu M, Tang H, Leng D, Hu S, Lu R, Wan W and Yuan S: MicroRNA-7 exerts antiangiogenic effect on colorectal cancer via ERK signaling. J Surg Res 240: 48-59, 2019.

22. Cui J, Li W, Liu G, Chen X, Gao X, Lu H and Lin D: A novel circular RNA, hsa_circ_0043278, acts as a potential biomarker and promotes non-small cell lung cancer cell proliferation and migration by regulating miR-520f. Artif Cells Nanomed Biotechnol 47: 810-821, 2019.
23. Galoian KA, Guettouche T, Issac B, Qureshi A and Temple HT: Regulation of onco and tumor suppressor MiRNAs by mTORC1 inhibitor PRP-1 in human chondrosarcoma. Tumour Biol 35 2335-2341, 2014.

24. Wang H: Predicting cancer-related MiRNAs using expression profiles in tumor tissue. Curr Pharm Biotechnol 15: 438-444, 2014.

25. Thomas J, Ohtsuka M, Pichler $M$ and Ling H: MicroRNAs: Clinical relevance in colorectal cancer. Int J Mol Sci 16 28063-28076, 2015.

26. Xie $\mathrm{X}, \mathrm{Xu} \mathrm{X}$, Sun $\mathrm{C}$ and $\mathrm{Yu} \mathrm{Z}$ : Long intergenic noncoding RNA SNHG16 interacts with miR-195 to promote proliferation, invasion and tumorigenesis in hepatocellular carcinoma. Exp Cell Res 383: 111501, 2019

27. Chen LP, Zhang NN, Ren XQ, He J and Li Y: miR-103/miR-195/miR-15b regulate SALL4 and inhibit proliferation and migration in Glioma. Molecules 23: 2938, 2018.

28. Li B, Wang S and Wang S: MiR-195 suppresses colon cancer proliferation and metastasis by targeting WNT3A. Mol Genet Genomics 293: 1245-1253, 2018.

29. Maroof H, Irani S, Arianna A, Vider J, Gopalan V and Lam AK Interactions of vascular endothelial growth factor and p53 with miR-195 in thyroid carcinoma: Possible therapeutic targets in aggressive thyroid cancers. Curr Cancer Drug Targets 19 561-570, 2019.

30. Humphreys KJ, McKinnon RA and Michael MZ: miR-18a inhibits CDC42 and plays a tumour suppressor role in colorectal cancer cells. PLoS One 9: e112288, 2014.

31. Satterfield L, Shuck R, Kurenbekova L, Allen-Rhoades W, Edwards D, Huang S, Rajapakshe K, Coarfa C, Donehower LA and Yustein JT: miR-130b directly targets ARHGAP1 to drive activation of a metastatic CDC42-PAK1-AP1 positive feedback loop in Ewing sarcoma. Int J Cancer 141: 2062-2075, 2017.

This work is licensed under a Creative Commons Attribution-NonCommercial-NoDerivatives 4.0 International (CC BY-NC-ND 4.0) License. 